\title{
Case Study on E-Business V Corp. Software Project Risk Management with Interpretive Structural Modeling
}

\author{
Jiangping Wan, Zhong Wang \\ School of Business Administration, South China University of Technology, Guangzhou, China \\ Email: csjpwan@scut.edu.cn, 1790276828@qq.com \\ Received 6 February 2015; accepted 23 March 2015; published 27 March 2015 \\ Copyright $@ 2015$ by authors and Scientific Research Publishing Inc. \\ This work is licensed under the Creative Commons Attribution International License (CC BY). \\ http://creativecommons.org/licenses/by/4.0/

(c) (i) Open Access

\section{Abstract}

The comprehensive risk management system based on the software project features of $\mathrm{V}$ Corp. is established. Four original risk factors are found with interpretive structural modeling, including analysis risk of product design, communication risk, human resource risk and decision making risk. Finally, some solutions are put forward to help e-business V Corp. improve the ability of software project risk management.

\section{Keywords}

Software Project Management, Comprehensive Risk Management System, Interpretive Structural Modeling, E-Business, Software, Case Study

\section{Introduction}

Today, the information technology has become one of the core competitiveness of e-business enterprises. Most of e-business businesses rely on information technology. E-business is the combination of "modern information technology" and "business", to some extent, e-business enterprises compete at the information technology among enterprises. With the expansion of scale and scope of the market, it becomes a trend for software project management to be complicated and short cycled.

The e-business systems of V Corp. involve all fields which make business process electronic, digital and networked, including B2C website, logistics, finance, customer service, management etc. The e-business systems mainly consist of various subsystems, such as website system, supplier system, logistics system, information platform, marketing system and customer service system. These subsystems are closely coordinated with each other and indispensable. But with the increasing of the business and the expansion of the market, software 
requirements are increasing so fast that companies often make software projects behind schedule and cause economic losses for lack of project risk management. Therefore, we constructed a risk structure model for e-business V Corp. and then proposed several solutions to deal with the four original risks. The paper is organized as follows: Section 2 is literature review, Section 3 is e-business V Corp. software project risk management analysis, Section 4 is to construct a software project risks structure model with interpretive structural modeling (ISM), Section 5 is the analysis and solutions for original risk factors of e-business V Corp. software project, and Section 6 is conclusion.

\section{Literature Review}

The software risk management involves two primary steps each with three subsidiary steps [1]. The first primary step, risk assessment, involves risk identification, risk analysis, and risk prioritization: 1) Risk identification produces lists of the project-specific risk items likely to compromise a project's success. Typical risk identification techniques include checklists, examination of decision drivers, comparison with experience (assumption analysis), and decomposition; 2) Risk analysis assesses the loss probability and loss magnitude for each identified risk item, and it assesses compound risks in risk item interactions. Typical techniques include performance models, cost models, network analysis, statistical decision analysis, and quality-factor (like reliability, availability, and security) analysis; 3) Risk prioritization produces a ranked ordering of the risk items identified and analyzed. Typical techniques include risk-exposure analysis, risk-reduction leverage analysis (particularly involving cost-benefit analysis), and Delphi or group-consensus techniques. The second primary step, risk control, involves risk-management planning, risk resolution, and risk monitoring: 1) Risk-management planning helps prepare you to address each risk item (for example, via information buying, risk avoidance, risk transfer, or risk reduction), including the coordination of the individual risk-item plans with each other and with the overall project plan. Typical techniques include checklists of risk-resolution techniques, cost benefit analysis, and standard risk management plan outlines, forms, and elements; 2) Risk resolution produces a situation in which the risk items are eliminated or otherwise resolved (for example, risk avoidance via relaxation of requirements). Typical techniques include proto-types, simulations, benchmarks, mission analyses, key-personnel agreements, design-to-cost approaches, and incremental development; 3) Risk monitoring involves tracking the project's progress toward resolving its risk items and taking corrective action where appropriate. Typical techniques include milestone tracking and a top 10 risk item list that is highlighted at each weekly, monthly, or milestone project review and followed up appropriately with reassessment of the risk item or corrective action.

J. P. Wan, D. Wan, and H. Zhang identify the risks of CN Group which is working at software outsourcing projects between Hong Kong and Guangdong, discovers the causal relationships among the risk factors, and constructs corresponding risk structure model with ISM. Five original risk factors are identified, including contracts risk, requirements definition and change, lack of communication, political and legal environment differences, and exchange rate fluctuations [2]. J. P. Wan and D. J. Li figure out eleven kinds of common mindbugs among the twenty five kinds of mindbugs with questionnaire. The relationship between the six original risk factors of implementation of the information technology service management (ITSM) project and these common mindbugs are also identified [3]. J. P. Wan and J. J. Hou study the possible risk factors during SAP Business One implementation with depth interview. The results are then adjusted by experts. 20 categories of risk factors that are totally 49 factors are found. Based on the risk factors during the SAP Business One implementation, questionnaire is used to study the key risk factors of SAP Business One implementation. The study illustrates that the structure is olive-like, in which the risk of data import is on the top, and the risk of senior managers is on the bottom [4]. J. P. Wan, Y.H. Cao and J. J. Hou study the comprehensive risk management system with the software project features of H Corp., the causal relationships among risks are discovered, and corresponding risk structure model is established with ISM. Five original risks are identified, including requirements analysis risk, project communication risk, schedule risk, risk of system design, and risk of project cooperation [5].

\section{Overview of E-Business V Corp. and Its Software Project}

The e-business V Corp., a Chinese company listed on the New York Stock Exchange, is a famous website that specializes in sample sales; its main business is the online sample sales of brand merchandise including luxury clothing, shoes, luggage and bags, household goods, cosmetics, and luxury goods etc. Today, it has established some business platforms such as supplier relationship management platform, marketing platform, mobile terminal 
platform, payment platform, Customer Relationship Management (CRM) platform and vendor financing platform. Communications among platforms need go through standard interface or layer which has clear information security requirements.

In our understanding, the features of e-business V Corp. software projects are as follows: 1) Software requirements are complicated, not only business department can make requests but product design department and technical department can also raise requirements. 2) Business requirements usually involve multiple platforms which have strong links with each other. Therefore it is very important to study correlation analysis among platforms at production design period. 3) V Corp. operates under functional organization structure, business requirements usually are raised by multiple departments, and many project stakeholders are involved. 4) To respond quickly and flexibly to changing business needs, V Corp. must iterate projects rapidly, and multi projects are often implemented at the same time. 5) Project management office coordinates and manages all project resources. Teamwork is an essential part of a successful project, and PMO has an important significance in cross team projects. 6) Software project implementation processes are under serious specifications, including design, research and develop, test, implementation, end of the project etc.

\section{Establish Risk Factors Interpretative Structure Model}

ISM method can be divided into the following steps: 1) Implement the ISM group; 2) Set the key issues; 3) Select the factors have influence on the key issues of the system; 4) List the correlation of the factors; 5) Establish the adjacency matrix and accessible matrix, according to the correlation; 6) Breakdown the accessible matrix and build the structure model; 7) Establish the interpretative structure model based on the structure mode [6].

\subsection{Identify Key Risk Factors of E-Business V Crop. Software Project}

We consulted experts with Delphi, including project managers, product managers, developers, testers, business personnel, software development and the internal control manager, and QA, etc. Based on implementation of e-business V Crop. software project, 24 risk factors are identified. By the way of calculating variable coefficient, ten major risk factors are figured out as follows Table 1 (i.e. adjacency matrix).

\subsection{Build Reachable Matrix}

For 10 key risk factors $K_{i}$ of V. Crop. software project ( $i=1,2,3 \ldots 10$ ), "1" means $K_{i}$ has influence on $K_{j}$, otherwise, " 0 " is used. The relationships between row factor and column factor can be illustrated as Table 2.

The reachable matrix is constructed with WINISM1.1 as Figure 1.

\subsection{Build Re-Order Reachable Matrix}

The set for each factor $K_{i}$ is obtained with the reachable matrix $M$ :

$$
\begin{aligned}
& K_{0} K_{1} K_{2} K_{3} K_{4} K_{5} K_{6} K_{7} K_{8} K_{9} K_{10} \\
& K_{0}\left(\begin{array}{lllllllllll}
1 & 0 & 0 & 0 & 0 & 0 & 0 & 0 & 0 & 0 & 0
\end{array}\right) \\
& \begin{array}{lllllllllllll}
K_{1} & 1 & 1 & 1 & 1 & 1 & 0 & 1 & 0 & 0 & 0 & 0
\end{array} \\
& \begin{array}{lllllllllllll}
K_{2} & 1 & 0 & 1 & 1 & 1 & 0 & 1 & 0 & 0 & 0 & 0
\end{array}
\end{aligned}
$$

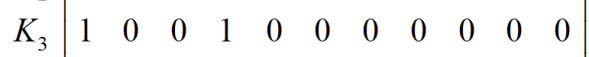

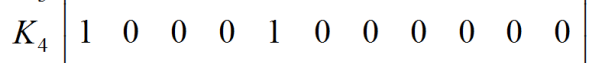

$$
\begin{aligned}
& M=\left[M_{i j}\right]=K_{5}\left[\begin{array}{llllllllllll}
1 & 0 & 1 & 1 & 1 & 1 & 1 & 1 & 1 & 0 & 0
\end{array}\right.
\end{aligned}
$$

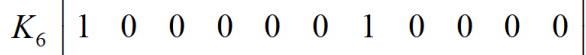

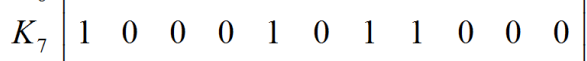

$$
\begin{aligned}
& \begin{array}{l|lllllllllll}
K_{8} & 1 & 0 & 0 & 1 & 1 & 0 & 1 & 0 & 1 & 0 & 0
\end{array} \\
& \left.\begin{array}{l|lllllllllll}
K_{9} & 1 & 0 & 1 & 1 & 1 & 0 & 1 & 1 & 1 & 1 & 0 \\
K_{10} & 1 & 0 & 1 & 0 & 1 & 0 & 1 & 1 & 0 & 0 & 1
\end{array}\right)
\end{aligned}
$$

Figure 1. Reachable matrix. 
Table 1. 10 key risk factors of e-business V Corp. software project.

\begin{tabular}{|c|c|c|}
\hline Code & Risk factors & Description \\
\hline$K_{1}$ & Analysis risk of product design & System analysts don’t perform feasibility analysis which leads to biases. \\
\hline$K_{2}$ & Requirements change risk & $\begin{array}{l}\text { Business department always raises new requirements or changes previous } \\
\text { requirements, which leads to expanding project. }\end{array}$ \\
\hline$K_{3}$ & Technology change risk & $\begin{array}{l}\text { Change technology because previous design cannot meet requirements, it may have } \\
\text { an impact on development progress. }\end{array}$ \\
\hline$K_{4}$ & Software quality risk & $\begin{array}{c}\text { Testers failed to find bugs duo to carelessness, there might be a problem after } \\
\text { publishing software. }\end{array}$ \\
\hline$K_{5}$ & Communication risk & Communication mechanism doesn’t work across project teams. \\
\hline$K_{6}$ & Schedule risk & Failed to finish the project on schedule \\
\hline$K_{7}$ & Software release risk & $\begin{array}{c}\text { Release plan faces problems because technology cannot support it or released } \\
\text { software has a side effect on online business. }\end{array}$ \\
\hline$K_{8}$ & Project management risk & System of mechanism, progress and emergency management is incomplete. \\
\hline$K_{9}$ & Human resources risk & Employees especially technical experts run off. \\
\hline$K_{10}$ & Decision making risk & Make wrong decisions or failed to make decisions in time. \\
\hline
\end{tabular}

Table 2. Relationships between row factor and column factor.

\begin{tabular}{ccccccccccccc}
\hline & $K_{0}$ & $K_{1}$ & $K_{2}$ & $K_{3}$ & $K_{4}$ & $K_{5}$ & $K_{6}$ & $K_{7}$ & $K_{8}$ & $K_{9}$ & $K_{10}$ \\
\hline$K_{0}$ & 1 & 0 & 0 & 0 & 0 & 0 & 0 & 0 & 0 & 0 & 0 \\
$K_{1}$ & 1 & 1 & 1 & 1 & 1 & 0 & 1 & 0 & 0 & 0 & 0 \\
$K_{2}$ & 1 & 0 & 1 & 1 & 1 & 0 & 1 & 0 & 0 & 0 & 0 \\
$K_{3}$ & 1 & 0 & 0 & 1 & 0 & 0 & 0 & 0 & 0 & 0 & 0 \\
$K_{4}$ & 1 & 0 & 0 & 0 & 1 & 0 & 0 & 0 & 0 & 0 & 0 \\
$K_{5}$ & 1 & 0 & 1 & 1 & 1 & 1 & 1 & 1 & 1 & 0 & 0 \\
$K_{6}$ & 1 & 0 & 0 & 0 & 0 & 0 & 1 & 0 & 0 & 0 & 0 \\
$K_{7}$ & 1 & 0 & 0 & 0 & 1 & 0 & 1 & 1 & 0 & 0 & 0 \\
$K_{8}$ & 1 & 0 & 0 & 1 & 1 & 0 & 1 & 0 & 1 & 0 & 0 \\
$K_{9}$ & 1 & 0 & 1 & 1 & 1 & 0 & 1 & 1 & 1 & 1 \\
$K_{10}$ & 1 & 0 & 1 & 0 & 1 & 0 & 1 & 1 & 0 & 0 \\
\hline
\end{tabular}

$$
\begin{array}{r}
P\left(K_{i}\right)=\left\{K_{j} m_{i j}=1\right\} \\
Q\left(K_{i}\right)=\left\{K_{j} m_{j i}=1\right\} \\
P\left(K_{i}\right) \cap Q\left(K_{i}\right)=T\left(K_{i}\right)
\end{array}
$$

$P\left(K_{i}\right)$ is called to reachable set, namely the set of all the reachable factors from factor $K_{i}$. $Q\left(K_{i}\right)$, called advanced set, refers to the set of all the factors can reach $K_{i} \cdot Q\left(R_{i}\right)$ means the universal set, which is the set of all the factors both belong to the reachable set and the advanced set (Table 3 ).

Because $i=0$ meets $R\left(K_{i}\right) \cap Q\left(K_{i}\right)=R\left(K_{i}\right)$, Stage $1=\left\{K_{0}\right\}$. The relationship description of the top 10 risk factors above is not intuitive enough. To express the relationship more clearly, the hierarchy is further analyzed (Table 4).

\subsection{Establish the Interpretative Structural Model of 10 Key Risk Factors}

According the results above, re-order reachable matrix is built as Figure 2. 


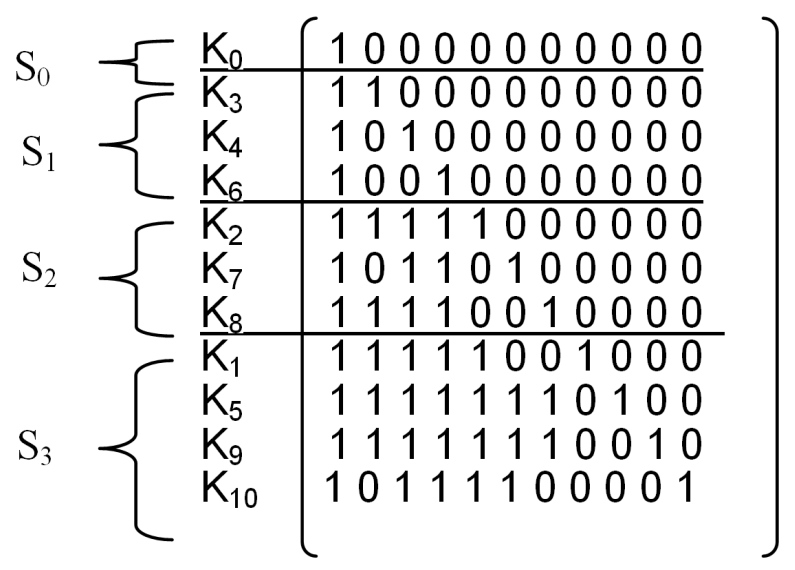

Figure 2. Re-order reachable matrix.

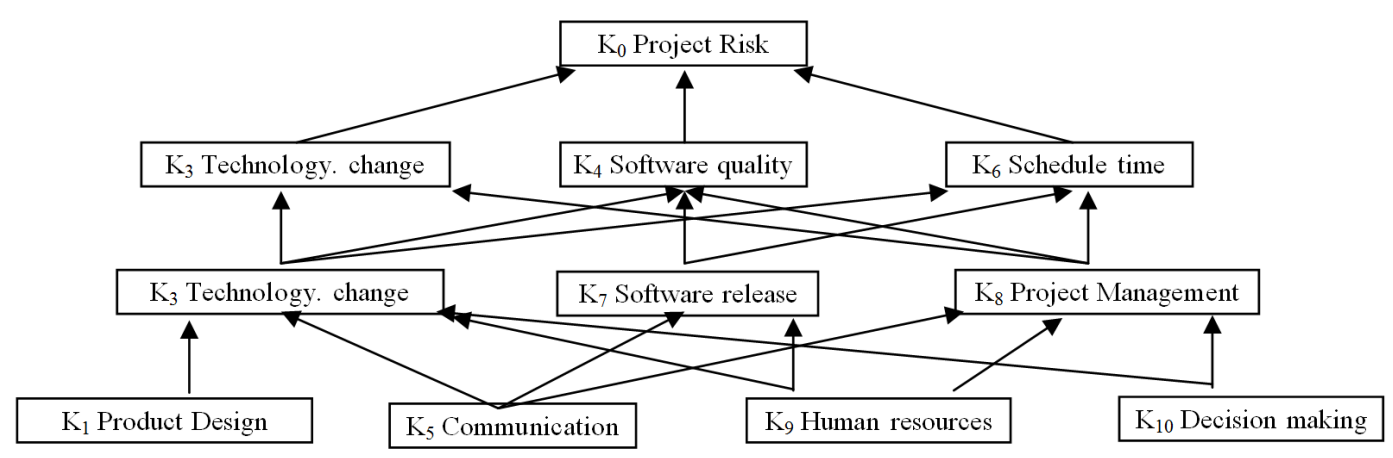

Figure 3. Interpretative structure model of e-business V Corp. software project risks.

Table 3. Relationships between row factor and column factor.

\begin{tabular}{cccc}
\hline & $R\left(K_{i}\right)$ & $Q\left(K_{i}\right)$ & $T\left(K_{i}\right)$ \\
\hline$K_{0}$ & 0 & $0,1,2,3,4,5,6,7,8,9,10$ & 0 \\
$K_{1}$ & $0,1,2,3,4,6$ & 1 & 1 \\
$K_{2}$ & $0,2,3,4,6$ & $1,2,5,9,10$ & 2 \\
$K_{3}$ & 0,3 & $1,2,3,5,8,9$ & 3 \\
$K_{4}$ & 0,4 & $1,2,4,5,7,8,9,10$ & 5 \\
$K_{5}$ & $0,2,3,4,5,6,7,8$ & 5 \\
$K_{6}$ & 0,6 & $1,2,5,6,7,8,9,10$ & 6 \\
$K_{7}$ & $0,4,6,7$ & $5,7,9,10$ & 7 \\
$K_{8}$ & $0,3,4,6,8$ & $5,8,9$ & 8 \\
$K_{9}$ & $0,2,3,4,6,7,8,9$ & 9 & 9 \\
$K_{10}$ & $0,2,4,6,7,10$ & 10 & 10 \\
\hline
\end{tabular}

\subsection{Analyze the Interpretive Structural Model}

Based on re-order reachable matrix above, the interpretative structural model of 10 key risk factors is established (Figure 3). 
Table 4. The hierarchy process of the top 10 risk factors of e-business V Corp. software project.

\begin{tabular}{|c|c|c|c|}
\hline$K_{i}$ & $P\left(K_{i}\right)$ & $Q\left(K_{i}\right)$ & $T\left(K_{i}\right)$ \\
\hline \multicolumn{4}{|c|}{ Stage $2=\left\{K_{3}, K_{4}, K_{6}\right\}$} \\
\hline$K_{1}$ & $1,2,3,4,6$ & 1 & 1 \\
\hline$K_{2}$ & $2,3,4,6$ & $1,2,5,9,10$ & 2 \\
\hline$K_{3}$ & 3 & $1,2,3,5,8,9$ & 3 \\
\hline$K_{4}$ & 4 & $1,2,4,5,7,8,9,10$ & 4 \\
\hline$K_{5}$ & $2,3,4,5,6,7,8$ & 5 & 5 \\
\hline$K_{6}$ & 6 & $1,2,5,6,7,8,9,10$ & 6 \\
\hline$K_{7}$ & $4,6,7$ & $5,7,9,10$ & 7 \\
\hline$K_{8}$ & $3,4,6,8$ & $5,8,9$ & 8 \\
\hline$K_{9}$ & $2,3,4,6,7,8,9$ & 9 & 9 \\
\hline$K_{10}$ & $2,4,6,7,10$ & 10 & 10 \\
\hline \multicolumn{4}{|c|}{ Stage $3=\left\{K_{2}, K_{7}, K_{8}\right\}$} \\
\hline$K_{1}$ & 1,2 & 1 & 1 \\
\hline$K_{2}$ & 2 & $1,2,5,9,10$ & 2 \\
\hline$K_{5}$ & $2,5,7,8$ & 5 & 5 \\
\hline$K_{7}$ & 7 & $5,7,9,10$ & 7 \\
\hline$K_{8}$ & 8 & $5,8,9$ & 8 \\
\hline$K_{9}$ & $2,7,8,9$ & 9 & 9 \\
\hline$K_{10}$ & $2,7,10$ & 10 & 10 \\
\hline \multicolumn{4}{|c|}{ Stage $4=\left\{K_{1}, K_{5}, K_{9}, K_{10}\right\}$} \\
\hline$K_{1}$ & 1 & 1 & 1 \\
\hline$K_{5}$ & 5 & 5 & 5 \\
\hline$K_{9}$ & 9 & 9 & 9 \\
\hline$K_{10}$ & 10 & 10 & 10 \\
\hline
\end{tabular}

\section{Analysis and Solutions for E-Business V Corp. Software Project Original Risks}

The four original risks of e-business V Corp. software project are identified, these are analysis risk of product design, communication risk, human resource risk and decision making risk. We will study these risks further and try to put forward corresponding solutions.

\subsection{Analysis Risk of Product Design}

It's hard for demanders to clearly express their real requirements, communication barriers between demanders and designers, changing requirements over time, all of those lead to analysis risk of product design. We give suggestions as follows: 1 ) Set up the requirements analysis mechanism, and release standardized management of input and output of product design and analysis; 2) Try to figure out real requirements as clearly as possible at the product design stage, it should have a specific mechanism to change requirements; 3) Sufficiently communicate with demanders when researching requirements, decrease risk of misunderstanding the product design stage, it should have a specific mechanism to change requirements; 4) Sufficiently communicate with demanders when researching requirements, decrease risk of misunderstanding. 


\subsection{Communication Risk}

When implementing project, demanders, designers and developers may have different understanding of product requirements and project schedule, due to lack of communication or inefficient communication. We give suggestions as follows: 1) Set up communication mechanism, including communication methods, tools and frequency etc. 2) Make project communication plans, carry out plans and check results regularly after communication.

\subsection{Human Resource Risk}

Company sometimes doesn't have enough technicians, underestimates the quantity of project human resources, or works on multiple projects simultaneously, which may lead to project human resource risk. We can take solutions as follows: 1) Discipline entire project team to take part in project evaluation so that every member can understand project requirements and avoid biases of estimating human resources; 2) Make unified management of project human resources with project management software; 3) Set up project risk reporting mechanism. When project human resource risk occurs, we can take measures quickly and finish project milestone on time.

\subsection{Decision-Making Risk}

Unfamiliar with project objectives, insufficient decision making information can lead to project decision-making risk. We give suggestions as follows: 1) Set up project discussion team, all team members have discussion, analyze and then make decision; 2) Project members assist project manager to collect information and ensure the information truthful, accurate and complete; 3) Set up project training team, organize employees to study project decision making, information collecting, sorting and analyzing regularly.

\section{Conclusion}

E-business is the combination of "modern information technology" and "business", to some extent, e-business enterprises compete at the information technology among enterprises. The four original risks of software project are identified, including analysis risk of product design, communication risk, human resource risk and decision making risk with V Corp. case study. We also put forward suggestions to help e-business V Corp. improve the ability of software project risk management. We believe that the research is helpful for both the software project risk management of e-business enterprises and software project risk management study in China.

\section{Acknowledgements}

Thanks for helpful discussion with Mr. Wenlv Chen, and Mr. Jianzhang Li et al.

\section{References}

[1] Boehm, B.W. (1991) Software Risk Management: Principles and Practices. IEEE Software, 8, 32-41. http://dx.doi.org/10.1109/52.62930

[2] Wan, J.P., Wan, D. and Zhang, H. (2010) Case Study on Business Risk Management for Software Outsourcing Service Provider with ISM. Technology and Investment, 1, 257-266. http://dx.doi.org/10.4236/ti.2010.14033

[3] Wan, J.P. and Wan, D. (2011) Analysis on the Mindbugs in Information Technology Service Management Project Implementation. Technology and Investment, 2, 184-192. http://dx.doi.org/10.4236/ti.2011.23019

[4] Wan, J.P. and Hou, J.J. (2012) Research on SAP Business One Implementation Risk Factors with Interpretive Structural Model. Journal of Software Engineering and Applications, 5, 147-155. http://dx.doi.org/10.4236/jsea.2012.53022

[5] Wan, J.P., Cao, Y.H. and Hou, J.J. (2013) Case Study on H Corp. Software Project Risk Management with ISM. Technology and Investment, 4, 145-152. http://dx.doi.org/10.4236/ti.2013.43017

[6] Warfield, J.N. (2003) The Mathematics of Structure. AJAR Publishing Company, Palm Harbor. 